\title{
Bridging the Gap Between Micro and Nanotechnology: Using Lab-on-a-Chip to Enable Nanosensors for Genomics, Proteomics, and Diagnostic Screening
}

\author{
Jonathan M. Cooper, Erik A. Johannessen, and David R.S. Cumming \\ Department of Electronics and Electrical Engineering, University of Glasgow, \\ Glasgow, G12 8LT, UK \\ jmcooper@elec.gla.ac.uk
}

\begin{abstract}
The growing need for accurate and fast methods of DNA and protein determination in the post human genome era has generated considerable interest in the development of new microfluidic analytical platforms, fabricated using methods adapted from the semi-conductor industry. These methods have resulted in the development of the Lab-on-a-Chip concept, a technology which often involves having a miniaturised biochip (as an analytical device), with rather larger instrumentation associated with the control of the associated sensors and of fluidics. This talk will explore the development of new Lab-ona-Chip platforms for DNA, protein and cell screening, using microfluidics as a packaging technology in order to enable advances in nanoscale science to be implemented in a Lab-on-a-Chip format. The talk will also show how system on a chip methods can be integrated with Lab-on-a-Chip devices to create remote and distributed intelligent sensors, which can be used in a variety of diagnostic applications, including for example chemical sensing within the GI tract.
\end{abstract}

\section{International Context of the Work}

The invention of the transistor enabled the first radiotelemetry capsules, which utilised simple circuits for in vivo telemetric studies of the gastro-intestinal (GI) tract [1]. These units could only transmit from a single sensor channel, and were difficult to assemble due to the use of discrete components [2]. The measurement parameters consisted of either temperature, $\mathrm{pH}$ or pressure, and the first attempts of conducting real time non-invasive physiological measurements suffered from poor reliability, low sensitivity and short lifetimes of the devices. The first successful $\mathrm{pH}$ gut profiles were achieved in 1972 [3], with subsequent improvements in sensitivity and lifetime [4, 5]. Single channel radiotelemetry capsules have since been applied for the detection of disease and abnormalities in the GI tract [6-8] where restricted access prevents the use of traditional endoscopy [9].

Most radiotelemetry capsules utilise laboratory type sensors such as glass $\mathrm{pH}$ electrodes, resistance thermometers [10] or moving inductive coils as pressure transducers [11]. The relatively large size of these sensors limits the functional 
complexity of the pill for a given size of capsule. Adapting existing semiconductor fabrication technologies to sensor development [12-17] has enabled the development of highly functional units for data collection, whilst the exploitation of integrated circuitry for sensor control, signal conditioning and wireless transmission [18] has extended the concept of single channel radiotelemetry to remote distributed sensing from microelectronic pills.

\section{Current Activity at the University of Glasgow}

Our current research on sensor integration and onboard data processing has therefore focused on the development of microsystems capable of performing simultaneous multiparameter physiological analysis [19,20]. The technology has a range of applications in the detection of disease and abnormalities in medical research. The overall aim has been to deliver enhanced functionality, reduced size and power consumption, through system level integration on a common integrated circuit platform comprising sensors, analogue and digital signal processing, and signal transmission. We have already created a platform which comprises a novel analytical microsystem incorporating a four channel microsensor array for real time determination of temperature, $\mathrm{pH}$, conductivity and oxygen (work pioneered by professor Cooper). The sensors were fabricated using electron beam and photolithographic pattern integration, and were controlled by an application specific integrated circuit (ASIC), which sampled the data with 10 bit resolution prior to communication off chip as a single interleaved data stream. An integrated radio transmitter sends the signal to a local receiver (base station), prior to data acquisition on a computer (work pioneered by Dr Cumming). We have now presented real time wireless data transmission from a model in vitro experimental set-up, for the first time.

The sensors comprised a silicon diode to measure the body core temperature, whilst also compensating for temperature induced signal changes in the other sensors; an ion selective field effect transistor, ISFET to measure $\mathrm{pH}$; a pair of direct contact gold electrodes to measure conductivity; and a three-electrode electrochemical cell, to detect the level of dissolved oxygen in solution. All of these measurements will, in the future, be used to perform in vivo physiological analysis of the GI-tract. For example, temperature sensors will not only be used to measure changes in the body core temperature, but may also be identify local changes associated with tissue inflammation and ulcers. Likewise, the $\mathrm{pH}$ sensor may be used for the determination of the presence of pathological conditions associated with abnormal $\mathrm{pH}$ levels, particularly those associated with pancreatic disease and hypertension, inflammatory bowel disease, the activity of fermenting bacteria, the level of acid excretion, reflux to the oesophagus, and the effect of GI specific drugs on target organs. The conductivity sensor will be used to monitor the contents of the GI tract by measuring water and salt absorption, bile secretion and the breakdown of organic components into charged colloids. Finally, the oxygen sensor will measure the oxygen gradient from the proximal to the distal GI tract. This will, in future enable a variety of syndromes to be 
investigated including the growth of aerobic bacteria or bacterial infection concomitant with low oxygen tension, as well as the role of oxygen in the formation of radicals causing cellular injury and pathophysiological conditions (inflammation and gastric ulceration). The implementation of a generic oxygen sensor will also enable the development of first generation enzyme linked amperometric biosensors, thus greatly extending the range of future applications to include e.g. glucose and lactate sensing, as well as immunosensing protocols.
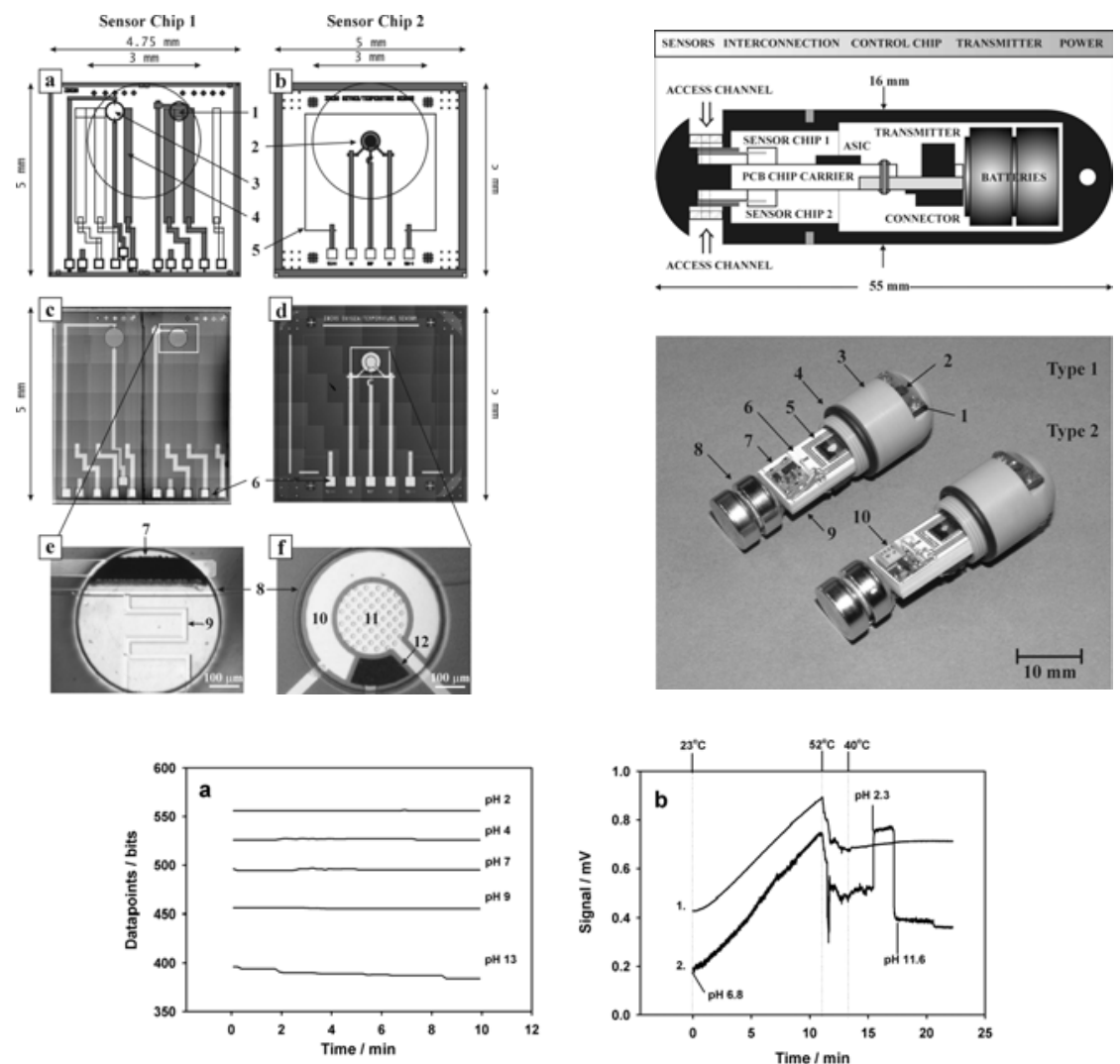

Figure 1: (Top left) showing the ISFET, temperature and conductivity sensor (Chip 1, a,c) and the electrochemical oxygen sensor (Chip 2, b, d). Figures e and f show detail of the $\mathrm{pH}$ and oxygen sensor, respectively; (Middle) Schematic (top right) and photo (below) of the Glasgow IDEAS capsule. Although the capsule is currently too large to swallow, the hybrid approach towards its construction provides considerable experimental flexibility. It is estimated that the volume of the pill could be readily reduced by ca. $40 \%$ through careful layout of the packaging and surface mount; (Bottom) a recording of $\mathrm{pH}$ and temperature using wireless transmission of data from a model gut system, showing the importance of temperature sensing. As expected the response of the $\mathrm{pH}$ sensor has a Nernstian dependence on temperature (although the reverse is not true, and the temperature sensor does not have a $\mathrm{pH}$ dependence). The Figure also shows that there is no signal cross-talk across the capsule, between sensors, despite the fact that they are located proximal to each other on the chip (and share the same microsystem for signal collection and transmission). 


\section{References}

1. Mackay, S., Jacobson, B.: Endoradiosonde. Nature 179 (1957) 1239-1240

2. Wolff, H.S.: The radio pill. New Scientist 12 (1961) 419-421

3. Meldrum, S.J., Watson, B. W., Riddle, H. C., Bown, R. L., Sladen, G.E.: pH Profile of gut as measured by radiotelemetry capsule. Brit. Med. Journal 2 (1972) 104-106

4. Evans, D. F., Pye, G., Bramley, R., Clark, A. G., Dyson, T. J., Hardcastle, J. D.: Measurement of gastrointestinal $\mathrm{pH}$ profiles in normal ambulant human subjects. Gut 29(8) (1988) 1035-1041

5. Colson, R. H., Watson, B. W., Fairlclough, P. D., Walker-Smith, J. A., Campell, C. A., Bellamy, D., Hinsull, S. M.: An accurate, long-term, $\mathrm{pH}$ sensitive radio pill for ingestion and implantation. Biotelem. Pat. Mon. 8(4) (1981) 213-227

6. Kadirkamanathan, S. S., Yazaki, E., Evans, D. F., Hepworth, C. C., Gong, F., Swain, C. P.: An ambulant porcine model of acid reflux used to evaluate endoscopic gastroplasty. Gut 44(6) (1999) 782-788

7. Press, A. G., Hauptmann, I. A., Hauptmann, L., Fuchs, B., Ewe, K., Ramadori, G.: Gastrointestinal $\mathrm{pH}$ profiles in patients with inflammatory bowel disease. Aliment Pharm. Therap. 12(7) (1998) 673-678

8. Pye, G., Evans, D. F., Ledingham, S., Hardcastle, J. D.: Gastrointestinal intraluminal pH in normal subjects and those with colorectal adenoma or carcinoma. Gut 31(12) (1990) 13551357

9. Iddan, G., Meron, G., Glukhovsky, A., Swain, P.: Wireless capsule endoscopy. Nature 405(6785) (2000) 417

10. Zhou, G. X.: Swallowable or implantable body temperature telemeter - Body temperature radio pill. Proc. IEEE Fifteenth Ann. Northeast Bioeng. Conference, Boston, MA, (1989) 165-166

11. Mackay, S.: Radio telemetering from within the body. Science 134 (1961) 1196-1202

12. Johannessen, E. A., Weaver, J. M. R., Bourova, L., Svoboda, P., Cobbold, P. H., Cooper, J. M.: Micromachined nanocalorimetric sensor for ultra-low-volume cell-based assays. Anal. Chem. 74(9) (2002) 2190-2197

13. Gardner, J. W.: Microsensors: principles and applications. Chichester, U.K.: Wiley, (1994) $1-331$

14. Gumbrecht, W., Peters, D., Schelter, W., Erhard, W., Henke, J., Steil, J., Sykora, U.: Integrated $\mathrm{pO} 2, \mathrm{pCO} 2, \mathrm{pH}$ sensor system for online blood monitoring. Sens. Actuators $\mathrm{B}$, 18-19(1-3) (1994) 704-708

15. Belmont-Herbert, C., Tercier, M. L., Buffle, J., Fiaccabrino, G. C., de Rooij, N. F., Koudelka-Hep, M.: Gel-integrated microelectrode arrays for direct voltammetric measurements of heavy metals in natural waters and other complex media. Anal. Chem. 70(14) (1998) 2949-2956

16. Jobst, G., Urban, G., Jachimowicz, A., Kohl, F., Tilado, O.: Thin film Clark-type oxygen sensor based on novel polymer membrane systems for in vivo and biosensor applications. Biosens. Bioelectron. 8(3-4) (1993) 123-128

17. Bergveld, P.: Development, operation, and application of the ion-sensitive field effect transistor as a tool for electrophysiology. IEEE Trans. Biomed. Eng. 19 (1972) 342-351

18. Asada, G., Burstein, A., Chong, D., Dong, M., Fielding, M., Kruglick, E., Ho, J., Lin, F. , Lin, T. H., Marcy, H., Mukai, R., Nelson, P., Newbery, F., Pister, K. S. J., Pottie, G., Sarcelize, H., Stafsudd, O. M., Valoff, S., Young, G., Kaiser, W. J.: Low power wireless communication and signal processing circuits for distributed microsystems. IEEE Int. Symp. Circuits and Systems 4 (1997) 2817-2820 
19. Tang, T.B., Johannessen, E.A., Wang, L., Astaras, A., Beaumont, S., Murray, A.F, Cooper, J.M., Cumming, D.R.S.: Miniature Wireless Integrated Multisensor Microsystem for Industrial and Biomedical Applications. IEEE Transactions in Sensors 2 (2003) 628-635

20. Johannessen, E.A., Tang, T.B., Wang, L., Astaras, A., Beaumont, S., Murray, A.F, Cumming, D.R.S., Cooper, J.M.: Remote Distributed Sensors for Biological Measurement in a Microsystems Format. Accepted in IEEE Transactions in Biology and Medicine, 2003 